\title{
El gobierno de Rafael Correa: posneoliberalismo, confrontación con los movimientos sociales y democracia plebiscitaria
}

\section{Rafael Correa's government: post-neoliberalism, confrontation with social movements and plebiscite democracy}

\section{Carlos de la Torre}

Carlos de la Torre es profesor e investigador en la Facultad Latinoamericana de Ciencias Sociales (FLACSO), Ecuador.

E-mail: cdelatorre@flacso.org.ec

\section{resumen}

Este trabajo analiza las ambigüedades del proyecto de refundación del gobierno de Rafael Correa para mejorar la calidad de la democracia en Ecuador. Correa prometió una revolución ciudadana que mejore los déficit de la democracia representativa. Al igual que en otros gobiernos de izquierda se hizo una asamblea refundacional. La nueva constitución amplió los derechos. Pero ya que el Presidente se ve como la encarnación de la revolución ciudadana y de la futura redención de la nación, no respeta el derecho al disenso ni el pluralismo. Su visión de democracia mayoritaria lo ha llevado a concentrar el poder en el ejecutivo y a subordinar a los diferentes poderes del Estado a éste. A la vez que el Gobierno ha incrementado el gasto social utiliza estrategias populistas para cooptar y desradicalizar a los movimientos sociales.

\section{palabras clave}

populismo / democracia plebsicitaria / giro a la izquierda

\section{summary}

This paper studies the ambiguous effects of Rafael Correa's project to refound the nation on the quality of democracy in Ecuador. In order to correct the deficits of representative institutions Correa promised a citizen's revolution. He convened a national assembly to write a new constitution. Even though the new constitution expanded citizens and collective rights the president does not respect pluralism or the right to dissent. The government majoritarian view of democracy has led to a concentration of power in the presidency. The government has simultaneously increased social expending and use populist strategies to coopt and deradicalize social movements.

\section{keywords}

populism / plebsicitaria democracy / left turn 
El gobierno de Rafael Correa forma parte del giro político a la izquierda en la región (Castañeda, 2006; French, 2009; Panizza, 2005; Weyland, 2009). Como otros gobiernos de izquierda, el régimen de Correa abandonó las políticas neoliberales, el Estado recobró un papel rector en la economía y se incrementó el gasto social para disminuir las desigualdades sociales. Al igual que los regímenes de izquierda contestataria de Hugo Chávez y de Evo Morales, las políticas económicas y sociales de su Gobierno se sustentan en el incremento de los precios de los recursos minerales (Weyland, 2009). Pero a diferencia del gobierno de Morales que se asienta en una red de organizaciones sociales, el régimen de Correa ha seguido el patrón populista de movilización desde el poder y ha buscado cooptar y desradicalizar a los movimientos sociales. A diferencia del gobierno de Hugo Chávez que ha experimentado con una serie de instituciones de democracia participativa como han sido los círculos bolivarianos y los consejos comunales, en los tres años de gestión el gobierno de Correa no ha creado instituciones de democracia participativa. El gobierno de Correa busca ligar directamente a la ciudadanía con el Presidente a través de dos estrategias mediáticas: la campaña permanente (Conaghan y de la Torre, 2008) y los enlaces ciudadanos que se transmiten por radio y televisión todos los sábados del año.

Este artículo tiene tres partes. La primera analiza la relación del gobierno de Correa con los movimientos sociales durante la asamblea constituyente del 20072008 y durante su gestión. La segunda estudia las estrategias mediáticas que buscan ligar al Presidente directamente con la ciudadanía y que lo forjan como la encarnación de las promesas de ruptura y de construcción de un nuevo orden social. La tercera estudia los efectos de su Gobierno en la calidad de la democracia representativa que había sufrido una larga crisis de representación que resultó en la destitución de tres presidentes electos.

\section{El gobierno de Correa y los movimientos sociales}

Rafael Correa ha tenido una carrera política meteórica. Hasta abril de 2005 fue profesor universitario en una universidad privada, la San Francisco de Quito. Fue conocido fuera de sus aulas y de los espacios académicos por sus intervenciones, sobre todo radiales, en contra de la dolarización y por sus críticas al modelo neoliberal. Luego del derrocamiento de Lucio Gutiérrez, el 20 de abril de 2005, Correa ocupó por dos meses la cartera de Economía en el gobierno de Alfredo Palacio. Fue el Ministro más controversial y quien se llevó la atención de los medios por sus confrontaciones verbales con los organismos internacionales y por sus intervenciones en contra del neoliberalismo. Luego de salir del gobierno, para participar en las elecciones presidenciales organizó el Movimiento Alianza País (AP) en noviembre de 2005. Durante la primera vuelta su estrategia fue arremeter en contra de los partidos políticos, presentando la contienda como una lucha ética y sin cuartel entre la partidocracia, que el pintó como la fuente de todos los males, y la ciudadanía encarnada en su persona. Para dar coherencia a su propuesta anti-partidos rehusó presentar candidatos al congreso promoviendo el voto nulo. 
Correa sintonizó con el rechazo de gran parte de la población a los partidos y a los políticos que habían sido importantes en la destitución del presidente Lucio Gutiérrez. Estos sentimientos también se expresaron en las manifestaciones en contra de Gutiérrez con la consigna "que se vayan todos" y en el ataque de ciudadanos en contra de los diputados el 15 de abril de 2005 en el que algunos fueron golpeados (Hurtado, 2005). Los sentimientos en contra de los políticos no estaban reducidos a Quito ni a una clase social. Un estudio basado en grupos focales y entrevistas en profundidad a personas de varias clases sociales, regiones y grupos étnicos realizado en julio de 2006 evidenció que para la mayor parte de los partícipes, los políticos eran los responsables de la corrupción que a su vez causaba problemas económicos como la pobreza y los trabajos indignos y mal remunerados en condiciones de precariedad laboral (Larrea, 2007). La campaña de Correa dio forma y sentido a este rechazo y presentó la Asamblea Constituyente como alternativa al dominio de la partidocracia y como la panacea que resolvería los problemas políticos, sociales y económicos de la nación.

El 26 de noviembre de 2006 Correa ganó la segunda vuelta a Álvaro Noboa con el $56.67 \%$ de los votos. La propuesta de convocar a una Asamblea Nacional Constituyente de plenos poderes y terminar la "larga noche neoliberal" fueron los ejes de su campaña. En el programa de gobierno de Alianza País se anotó que la Asamblea ayudará a construir una "democracia activa, radical y deliberativa" y que propiciará "un modelo participativo a través del cual todos los ciudadanos y ciudadanas puedan ejercer el poder, formar parte de las decisiones públicas y controlar la actuación de sus representantes políticos". ${ }^{1}$ La Asamblea Constituyente no fue vista solamente como un mecanismo para hacer reformas políticas. Propusieron crear "un proyecto de vida común, un acuerdo social amplio" en que la "sociedad movilizada tendrá que participar no sólo en la elección de asambleístas" sino que "adueñarse de la Constitución y luego presionar para que se cumpla lo acordado". ${ }^{2}$ El economista de izquierda Alberto Acosta, primer presidente de la asamblea, la vio "como una oportunidad para construir ciudadanía, para que la gente participe... Lo que queremos es que este nuevo trato, este nuevo proyecto de vida en común, ese pacto social que se vea reflejado en una Carta Fundamental, sea nuestro, de la ciudadanía". ${ }^{3}$

El 15 de abril de 2007 el $82 \%$ de los votos válidos fueron a favor de que se realice una asamblea constituyente de plenos poderes y en noviembre la alianza gobiernista Acuerdo País obtuvo 80 de los 130 representantes. A primera vista el contexto parecía favorable no sólo para que la agenda de los movimientos sociales se cristalice en la nueva Constitución, sino también para que las propuestas de radicalización de la democracia de Alianza País se materialicen. Pero, como lo señalaron Rocío Rosero, líder del movimiento de mujeres, y Nina Pacari, líder histórica del movimiento indígena, el país estaba ante una paradoja. Pese a que la izquierda esté en el poder lo que garantiza que la agenda posneoliberal de los movimientos sociales se materialice, algunas demandas culturales de los movimientos sociales, en palabras de estas líderes, estarían en peligro. ${ }^{4}$

Si bien hubo asambleístas comprometidas con las propuestas de su movimiento, dirigentes del movimiento de mujeres vieron con temor el que no se avance con su 
agenda de derechos sexuales y reproductivos pues consideraron que Alianza País está dominada por la figura del presidente Correa. Éste, que es un católico practicante, manifestó su negativa al aborto y al matrimonio gay. El liderazgo de AP para mantener la unidad en la asamblea decidió no destapar temas como estos, que podrían ocasionar fisuras. ${ }^{5}$ Algunas representantes de Acuerdo País marcharon por el derecho a la vida y lograron frenar las propuestas sobre aborto y matrimonio gay.

Pese a los recelos, en la nueva constitución no se dio un retroceso en las conquistas sobre derechos con respecto a la constitución de 1998 que muchas líderes del movimiento feminista vieron como suya y que la catalogaron como progresista (Rosero, Vela y Reyes, 2000). La nueva constitución avanzó en una serie de conquistas y derechos económicos de las mujeres. Además, en los textos constitucionales se recurrió a la ambigüedad para dejar abierta la puerta a la implementación de formas alternativas de familia a la nuclear heterosexual. Por ejemplo el artículo 67 de la Constitución de 2008 a la vez que reconoce la familia en sus diversos tipos, señala que el matrimonio es la unión entre hombre y mujer. Para aumentar la ambigüedad se reconoce la libertad de "decisión sobre la orientación sexual" (Ospina, 2009: 134).

La nueva constitución además profundizó el proceso de otorgar derechos colectivos a los indígenas y afrodescendientes que empezó con la constitución de 1998. La Constitución de 2008 designa al Estado ecuatoriano como intercultural y plurinacional. Se reconocen los territorios indígenas, afroecuatorianos y montubios, "se establece el 'sumak kawsay' o buen vivir como el objetivo a alcanzar en el proceso de desarrollo, la ampliación de los derechos colectivos, el reconocimiento de la justicia indígena" (Larrea, 2008: 80). Los movimientos ecologistas consiguieron el otorgamiento de derechos a la naturaleza. El movimiento sindical logró que termine la precarización y la tercerización laboral.

El proceso constituyente además fue participativo. "Los académicos ahora argumentan que para que una constitución sea verdaderamente democrática, el proceso a través del que se la escribe debe ser inclusivo, participativo y abierto" (Segura y Bejarano, 2004: 217). Los procesos constituyentes deben seguir el precepto de Thomas Paine, "las constituciones no son del gobierno, sino de los ciudadanos que constituyen un gobierno" (citado en Arato, 2005: 1-2). Con el afán de que el proceso sea participativo e incluyente se organizaron diez mesas constituyentes con la participación de legisladores de AP y de la oposición. ${ }^{6}$ Estas mesas recibieron a 1.500 delegaciones de distintos sectores sociales y 1.000 propuestas de partidos, organizaciones de la sociedad civil y aún de individuos. ${ }^{7}$ Los debates sobre interculturalidad y plurinacionalidad, por ejemplo, contaron con aportes de las organizaciones indígenas CONAIE y FENOCIN y de académicos como Boaventura de Sousa Santos, Galo Ramón y Catherine Walsh. Las mesas organizaron alrededor de setenta foros en varias ciudades del país sobre temas tales como la minería, el agua, los jóvenes, las políticas culturales, etc.

Durante la presidencia de Alberto Acosta se vivió un espíritu democrático dentro de la asamblea. La decisión de que ésta sesione en la pequeña ciudad de Montecristi, en la provincia de Manabí, obligó a que convivan los asambleístas. Éstos 
compartieron y comieron junto a todo el personal que trabaja en la asamblea, fenómeno no común en una sociedad marcada por las diferencias étnicas y de clase. Si bien el oficialismo tuvo mayoría en la asamblea, Alberto Acosta fue muy cuidadoso en dar el espacio necesario para que se discutan los artículos y los mandatos constitucionales, permitió que se escuchen las voces de la oposición y trató de incorporarlos en las decisiones.

Si bien Alberto Acosta coincidía en que la constitución debía reflejar un nuevo pacto social que fuera incluyente, tuvo que enfrentar tres obstáculos. El primero fue demostrar que la asamblea no era un apéndice del ejecutivo. Esto se dificultó por las características estructurales en las que se desarrolló la asamblea, sin un partido político del Gobierno y bajo el liderazgo carismático del presidente Correa. La asamblea durante la presidencia de Acosta caminó en una cuerda floja para demostrar su independencia y no dar la impresión de que la constitución era hecha a la medida no sólo de AP sino de los intereses de Rafael Correa. Temas tales como la reelección inmediata favorecida por Correa y por la mayor parte de asambleístas de AP y no aceptada por Acosta y una minoría en la asamblea, ensombrecieron la independencia de ésta. El Presidente de la república, además, tuvo varias reuniones con los asambleístas de AP para discutir problemáticas como los derechos de la mujer, la minería, etc. Si bien estas reuniones, que fueron a puerta cerrada y $\sin$ presencia de la prensa, según los partícipes tuvieron un carácter democrático y deliberativo, la prensa señaló que el ejecutivo impuso sus criterios. Sea cual fuese la verdad, estas reuniones fueron la oportunidad para que algunos asambleístas traten de demostrar su lealtad al líder carismático y en algunos temas controversiales se impuso el criterio de Correa. Por ejemplo se incluyó el nombre de Dios en la constitución, no se debatió el matrimonio gay, se aceptó la reelección presidencial. La impresión que hubo injerencia del ejecutivo se magnificó con la presencia de los delegados personales de Correa en la asamblea y con los rumores de que éstos a veces modificaron la redacción de los artículos constitucionales.

Estos problemas de falta de autonomía se magnificaron cuando Acosta fue obligado a renunciar a su cargo de presidente de la asamblea por una decisión del Buró Político de Alianza País en junio de 2008. Su renuncia no se debió a un pedido de los asambleístas sino a una decisión de Correa y su círculo íntimo del Polit Buró. Acosta fue reemplazado por Fernando Cordero quien se desempeñaba como vicepresidente de la asamblea. Durante el mandato de Cordero la asamblea aprobó los artículos sin mayor debate e imponiendo la agenda de la mayoría gobiernista. Las dudas sobre la autodeterminación de la asamblea quedaron despejadas por la poca independencia de ésta del ejecutivo en su última fase.

Un segundo problema que resultó en la separación de Acosta tuvo que ver con los tiempos. La visión de Acosta fue que para que la constitución sea duradera, la deliberación y la inclusión de la oposición era necesaria y que el proceso constituyente se debería extender. Correa, al igual que Hugo Chávez, buscó que el proceso constituyente se desarrollara rápidamente y que no se dilate en largas discusiones. Apoyándose en encuestas de opinión, Correa argumentó que la baja de popularidad de la asamblea, percibida como una especie de congreso, afectaría 
negativamente los resultados del referéndum aprobatorio. La deliberación fue vista como excesiva democracia y se buscó un presidente de la asamblea que agilice los procesos.

Un tercer problema de la constituyente fue que al asumir plenos poderes legislativos y al decretar un receso del congreso legislaron a través de los mandatos constituyentes. Por un lado, fue la oportunidad para hacer reformas importantes como eliminar la tercerización e intermediación laboral y la de regular y revisar los contratos mineros que se habían otorgado en gobiernos anteriores sin tomar en consideración criterios ecológicos y la opinión de las comunidades afectadas. Pero por el otro, los mandatos introdujeron criterios corporativistas y clientelares en la asamblea. Por ejemplo, en una discusión sobre el uso de dinero del fondo de solidaridad para la electricidad y la comunicación pude observar durante el trabajo de campo en la asamblea, cómo una asambleísta intentó condicionar su voto a cambio de la inclusión del nombre de su provincia como beneficiaria de estos fondos, con el propósito de demostrar a sus electores las ventajas que era capaz de obtener.

Una vez aprobada la nueva constitución con más del 60 por ciento de los votos podría haberse esperado una colaboración entre los movimientos sociales con el gobierno de Correa. Sin embargo, el Gobierno ha entrado en confrontación con varios sectores organizados de la sociedad como son los maestros, los sindicatos públicos, el movimiento indígena sobre todo la Confederación de Nacionalidades Indígenas del Ecuador (CONAIE) y sectores del ecologismo. Estos conflictos se explican por tres factores. El primero es que el Gobierno nacional, conformado por tecnócratas y científicos sociales de izquierda, se ve como la representación del interés nacional que está más allá de las agendas corporativas de los diferentes sectores de la sociedad civil. Como dijo Correa, "nuestra visión no puede ser otra que la nacional" (citado en Ospina, 2009: 4). El Gobierno está embarcado en un proceso de formación del Estado-nación y se ve en la necesidad de crear un Estado que recupere los espacios delegados a la sociedad civil y confunde los ámbitos de autonomía de sectores organizados con legados del neoliberalismo. Es así que se transfirió el control de la educación intercultural bilingüe del movimiento indígena al Estado y se han quitado fondos a las instituciones estatales que estaban controladas por los movimientos sociales como el consejo de la mujer y el consejo de nacionalidades y pueblos indígenas. También se ha pedido a todas las ONGs que se registren y se sometan a la tutela estatal. Se ha tratado de desmantelar al sindicato de maestros y de "limitar el sindicalismo público, impedir la agremiación de los empleados [públicos] y reducir al mínimo cualquier posibilidad de contratación colectiva" (Ospina, 2009: 5).

Estos intentos de crear un Estado que regule se basan en la noción de que el Estado es la "representación institucionalizada de la sociedad" y que su papel es "la planificación, organización sectorial y regional, adecuados modelos de gestión, racionalidad administrativa, rescate de las empresas públicas". ${ }^{8}$ Para que el Estado represente los intereses nacionales el Gobierno sostiene que debe ser rescatado de la injerencia de diferentes grupos corporativos como los gremios empresariales, los maestros, los empleados públicos y los liderazgos de los movimientos 
indígenas. Estos grupos al ser incorporados al Estado como funcionarios y como rectores de las políticas públicas para su sector viciaron y corrompieron, según dice el Gobierno, el carácter universalista de las políticas estatales con criterios particularistas. Es por esto que ahora se prohíbe que los diferentes grupos sociales sean jueces y parte de las políticas públicas que les afectan. Las políticas públicas y los organismos de control deben estar en manos de quienes puedan representar el interés general del Estado y no el particularismo de las corporaciones. Ahora los organismos de control estarán en manos del Consejo de Participación Ciudadana y Control Social. Este organismo estará integrado por siete personas elegidas por un concurso público de oposición y méritos. Tiene como funciones promover la participación y designar a las autoridades de Control, al Procurador General de la Nación, Superintendentes, Defensor del Pueblo, Defensor Público, Fiscal General del Estado, Contralor General, así como a los miembros del Consejo de la Judicatura, del Consejo Nacional Electoral y del Tribunal Contencioso Electoral (Pachano, 2010: 24).

Los afanes porque el Estado asuma el control de dependencias estatales que estaban en las manos de los movimientos sociales obviamente han despertado la oposición de los líderes de movimientos a los que se les quitan espacios de poder estatal que ellos vieron como sus conquistas. Por ejemplo, para el movimiento indígena el control de la educación intercultural bilingüe y del consejo de desarrollo para los pueblos y nacionalidades indígenas fue visto como conquista de sus luchas. A diferencia del Presidente de la república que dijo que el Consejo Nacional de la Mujer, el Consejo de Desarrollo de las Nacionalidades y de Pueblos del Ecuador y el Consejo de Desarrollo Afro-Ecuatoriano son "invenciones neoliberales", destacan que son conquistas de los movimientos sociales. ${ }^{9}$ El Gobierno abolió estos consejos y ha promovido que las agendas de género y de interculturalidad sean transversales a todas las políticas estatales. Esta iniciativa fue vista por líderes de los movimientos sociales como una estrategia para diluir el contenido de las propuestas de equidad de género y de interculturalidad. Por último, varios líderes de AP y personalidades del Gobierno han manifestado que ya que los movimientos sociales están en crisis y que su agenda ha sido corporatizada los liderazgos no tienen representatividad. En ausencia de representatividad de los líderes, el Gobierno no considera importante incluirlos en discusiones ni tener en cuenta sus agendas. Ya que el Presidente ha ganado varias elecciones con mayorías absolutas y de que goza de niveles altos de popularidad, no necesita de los liderazgos de los movimientos sociales. Además, el Presidente considera que los movimientos ecologista e indígena radicales son el mayor peligro para su proyecto. En varias intervenciones ha repetido estas palabras: "siempre dijimos que el mayor peligro para nuestro proyecto político, una vez derrotada sucesivamente en las urnas la derecha política, era el izquierdismo, ecologismo e indianismo infantil. ¡Qué lástima que no nos equivocamos en aquello!". ${ }^{10}$

Un segundo factor que explica los conflictos con los ecologistas y el movimiento indígena es la presencia de diferentes visiones sobre el desarrollo. Correa privilegia un modelo tecnocrático extractivista que comprende ampliar la explotación 
petrolera, y abrir el país a la minería a gran escala. Este modelo es cuestionado por los movimientos ecologistas e indígena que están en contra de la minería a gran escala y buscan una moratoria en la explotación petrolera (Acosta, 2009). Los movimientos indígenas y ecologistas también resienten la forma en la cual se discutieron las leyes de minería y de aguas sin realmente consultar o buscar la participación de las comunidades indígenas (Martínez Novo, 2009: 12). Según el Presidente, el Gobierno impulsará "una minería responsable y no podemos ser mendigos sentados en un saco de oro". Acusa a los ecologistas de ser financiados por ONGs extranjeras y pide a su pueblo que "no se dejen engañar, que confíen en su gobierno". ${ }^{11}$

El tercer factor que explica los conflictos del régimen con el movimiento indígena es la estrategia populista del Gobierno de movilización desde el poder (Oxhorn, 1998). El Gobierno busca cooptar y dividir a los movimientos sociales y algunos líderes indígenas que buscan surgir se alían con el movimiento PAIS para asegurar una carrera política y conseguir los fondos para hacer política clientelar en sus comunidades. El Gobierno además ha utilizado a organizaciones indígenas más pequeñas como la Federación Nacional de Organizaciones Campesinas, Indígenas y Negras (FENOCIN), ligada al Partido Socialista, y a la vieja Federación Ecuatoriana de Indios (FEI) del Partido Comunista que había casi desaparecido en los años 80 y 90, para fragmentar y cooptar a la organización más grande que es la CONAIE. Las políticas públicas del Gobierno como son los Bonos de la Dignidad que otorga 35 dólares al mes a las familias más pobres, los bonos de vivienda, los programas como Socio Páramo y Socio Bosque promueven además la imagen del presidente Correa como quien distribuye recursos a los más necesitados. Estas políticas que son bien recibidas por la gente común y corriente debilita a las organizaciones de la CONAIE y muchos líderes están optando por integrarse al movimiento PAIS.

\section{La política comunicacional y mediática del Gobierno}

Alianza País no se ha conformado en un partido político, tal vez por la fuerza de los sentimientos anti-partidos que están en su origen. Por lo pronto funciona como una red clientelar durante las diferentes elecciones y como un mecanismo para acceder a los puestos estatales. El gobierno de Correa tampoco se asienta en los movimientos sociales. En ausencia de un respaldo partidista y de una base en la sociedad civil, el Gobierno ha utilizado dos estrategias para ligar al líder directamente con el pueblo: la campaña permanente y los enlaces ciudadanos.

El Presidente está en campaña permanente para ganar elecciones en las que se juega la futura redención: "pueden decidir continuar con el cambio o volver al pasado". ${ }^{12}$ Después de asumir el poder en enero de 2007, Correa ganó las elecciones por el sí en el referéndum para llamar a una asamblea constituyente en abril del 2007. Luego sus candidatos obtuvieron la mayoría absoluta en la asamblea en septiembre del mismo año. Se aprobó la nueva constitución en septiembre del 2008 y en abril del 2009 fue electo presidente por segunda vez y en una sola vuelta electoral y su movimiento obtuvo una mayoría en el parlamento que ahora se llama asamblea. 
En la lógica de la campaña permanente los procesos de gobernar y de hacer campaña se fusionan y pierden sus diferencias (Ornstein y Mann, 2000). Correa explica que él es "el motivador" que debe subir la autoestima del pueblo ecuatoriano y que por esa razón está en campaña. Los expertos en manipulación mediática han asumido posiciones claves en su administración y cada acto de gobierno se basa en sondeos de opinión pública y en focus groups que ayudan a que los publicistas elaboren cuñas de televisión y otras estrategias mediáticas para vender su imagen, destrozar a sus opositores y crear la sensación de que se vive una revolución que despierta conspiraciones. ${ }^{13}$ Su gobierno se transforma así en un plebiscito permanente sobre la persona del líder (Conaghan y de la Torre, 2008). Como lo señala Catherine Conaghan, la presidencia de Correa es plebiscitaria en dos sentidos: ha tenido y tendrá que ganar elecciones y se basa en la comunicación directa, no mediada, ni institucionalizada, entre el ejecutivo y los electores. Este es un gobierno personalista. Afirma la autora: "Sin oposición de los partidos políticos o de la sociedad civil, con un movimiento electoral más que con un partido de gobierno, el desarrollo político del Ecuador parece que se asienta solamente en Correa: su personalidad, sus ambiciones y sus decisiones sobre que tipo de 'giro a la izquierda' son las más convenientes para el país. El que las intenciones de un hombre sean tan influyentes en la trayectoria del cambio es preocupante" (2008: 59).

Los medios de comunicación son centrales en estas estrategias que buscan ligar directamente al Presidente con los ciudadanos sin la intermediación de los partidos y de las instituciones democráticas. El Gobierno es el anunciante más grande en televisión. En 2009 utilizó 721 horas de publicidad pagada. ${ }^{14}$ Todas las semanas se da al menos una cadena de televisión en la que se informa de las actividades del Gobierno. La mayor parte del programa se centra en Correa que visita el país, inaugura y supervisa obras. ${ }^{15}$ En estas cadenas también se promueven las propuestas del Gobierno y se ataca a los opositores y a figuras mediáticas. Las cadenas recurren al nacionalismo con el slogan "¡la patria ya es de todos!" que aparece junto a la canción patriótica "patria querida". Así se da continuidad a los lemas electorales que apelaban al nacionalismo y que pintaban a Correa como la encarnación de los valores patrios: "pasión por la patria" y "la patria vuelve".

La innovación mediática más importante del gobierno de Rafael Correa son los enlaces ciudadanos que se transmiten en la radio y televisión pública que también incluye a los medios expropiados a empresarios nacionales por su no pago de deudas al Estado. ${ }^{16}$ Estos enlaces permiten que el Presidente se convierta en una figura carismática que simbólicamente es el "centro de la nación" que irradia su poder hacia todos sus rincones (Geertz, 1985). El poder se materializa en el verbo del Presidente que insulta y cuestiona la mediocridad de sus rivales. Exige más trabajo y mejores resultados a sus colaboradores. Halaga a su pueblo al que sirve trabajando sin descansar y al que explica didácticamente todas sus acciones y omisiones de la semana. Además y en términos más pragmáticos, en los enlaces Correa marca la agenda noticiosa del domingo, día bajo en noticias políticas. Los periodistas escuchan atentamente sus palabras en que cuestiona a la "prensa corrupta", da directrices y órdenes a sus colaboradores, denuncia 
a sus enemigos políticos y explica las diferentes acciones que emprenderá su Gobierno.

En los enlaces ciudadanos el Presidente entabla una relación no mediada con los ciudadanos. El show televisivo y radial permite crear redes de apoyo pues el día anterior el Presidente y su gabinete ampliado han dialogado con las autoridades locales de provincia y escuchado sus pedidos para obras y recursos. El enlace además ayuda a que semanalmente y por dos horas se renueve el lazo carismático entre el Presidente y sus electores que escuchan al menos parte del programa en las tiendas de los pueblos, en los autobuses o en sus hogares. Los enlaces se transmiten desde lugares remotos a los que casi nunca llegó un presidente y se invita a los pobladores a que estén presentes y a que aparezcan en la televisión. Al visitar lugares apartados, Correa refuerza su carisma pues al igual que los lobos y los reyes recorre su territorio buscando convertirse en el centro del orden social (Geertz, 1985).

Durante los enlaces se repite el mismo ritual. El Presidente se sienta en un podio alto desde donde diserta como si fuese el profesor que da cátedra a todos los ecuatorianos. Utiliza presentaciones en power point para ilustrar con cifras y datos técnicos sus políticas de gobierno. Las cátedras magistrales del Presidente son interrumpidas por el aplauso de los asistentes, o por las preguntas de Correa al auditorio que son contestadas con el sí o el no. Rara vez hay un diálogo entre el mandatario y su pueblo, aunque a veces se da el micrófono a alguna personalidad del Gobierno para que explique algún tema. De esta manera se escenifica claramente el poder: el Presidente- catedrático de la nación está por encima de un público que lo aclama pero que no tiene la posibilidad de entablar un diálogo crítico con el primer mandatario.

El Presidente hace un recorrido minucioso sobre todos sus actos oficiales. Parecería que hace un acto de rendición de cuentas o un acto de constricción en que recorre todo lo que le pasó a él y a la Patria cada semana. Estas intervenciones demuestran que él es la Patria, a la que sirve con verdadera fe y dedicación. El Presidente utiliza un lenguaje coloquial y los modismos lingüísticos de las clases populares guayaquileñas para demostrar que es igual al pueblo, que viene desde abajo y no es como los aniñados que desconocen a su pueblo. Pero a su vez el líder es una figura excepcional y es superior a las personas comunes que lo ven en vivo pues estudió con becas en las mejores universidades y consiguió un título de Ph.D. en los Estados Unidos. Utiliza el discurso técnico del economista que además maneja cifras e indicadores para presentar las iniciativas del gobierno. En un enlace por ejemplo explicó tres políticas de gobierno con lujo de detalles técnicos: la producción de medicinas genéricas, la ley de deportes, y el cobro de más impuestos y regalías a las petroleras extranjeras. Es así que el presidente de origen popular es a su vez un ser superior que maneja los códigos que pueden llevar al país a la modernidad y al desarrollo.

Para amenizar un programa que dura más de dos horas y en el que se presentan cifras y power points con organigramas de cómo reorganizar las dependencias del Estado, el Presidente hace chistes, imita burlonamente a sus adversarios, gesticula, 
ríe y se enfada. También pasa grabaciones de eventos en el Palacio de gobierno o de él visitando obras. Reclama en tono enérgico a sus subordinados cuando no han hecho bien su trabajo. Es así que las fallas son responsabilidades de otros y el líder refuerza su superioridad sobre la de los simples mortales que cometen errores. Invita a que le acompañen diferentes funcionarios para que expliquen leyes y políticas de Estado. Cuando se refiere a lo que llama las barbaridades de sus adversarios deja el tono de voz del catedrático. El Presidente se enrojece, sube el tono de voz, gesticula, se enfurece y descalifica a sus rivales como "mediocres". Durante el conflicto con el movimiento indígena por la ley de aguas se refirió al liderazgo de la CONAIE como "ponchos dorados", "la peluconería indígena" mientras que las cámara enfocaban a indígenas de su gobierno como Carlos Viteri y Pedro de la Cruz que se reían de sus palabras. Estos momentos de confrontación se sellan con consignas revolucionarias emitidas por el Presidente como por ejemplo "¡no pasarán!".

Los enlaces también sirven como espacios para dar cátedra sobre los derechos ciudadanos. En el Enlace 137, por ejemplo, el Presidente narró que un banco local le había cobrado tasas ilegales por servicios. Invitó a los presentes a que "aprendamos a reclamar" a las grandes empresas. Manifestó, "nosotros defendemos sueños, no negocios". Para demostrar su vocación de izquierda dijo que no le gustan los banqueros y que nunca almorzó con ellos, pero que no tiene más remedio que reunirse con los burgueses. Sus discursos anti-oligárquicos y en contra de los "aniñados" y de los "pelucones" le asemejan con la gente común y dignifican a los de abajo que se sienten representados e identificados en un presidente de origen popular pero superior a todos. Correa reconoce la valía de sectores de la población que son estigmatizados y discriminados como los jóvenes de las "pandillas los Latin King y los Ñecas", las prostitutas, la población privada de su libertad, los afroecuatorianos y las trabajadoras domésticas. ${ }^{17}$

La sección estelar de su programa se titula "la libertad de expresión ya es de todos" en clara referencia a las consignas de su gobierno que giran en torno al slogan "la patria ya es de todos". En esta sección cuestiona la veracidad de los medios que, según él, son instrumentos de sus dueños para hacer negocios y pasa segmentos de la canción de Piero que dice "todos los días y todos los días los diarios publicaban porquerías" y un fragmento de la canción de Víctor Heredia que dice, "mienten, mienten, que forma de mentir". Así transforma la política en una disputa sobre la credibilidad de su persona frente a la falta de credibilidad de los medios. De esta manera, a la vez que esgrime explicaciones técnicas para argumentar que la revolución ciudadana se basa en la planificación estatal y en el trabajo de un grupo de tecnócratas ilustrados, utiliza argumentos que personalizan la política como la lucha ética entre quien puede presentar mejor su imagen sin que importen los contenidos. A diferencia de líderes telepopulistas que transformaron la política en una lucha sobre símbolos y no sobre propuestas (Peri, 2004), Correa mezcla el telepopulismo con la disputa sobre políticas públicas con argumentos técnicos. Su populismo combina los apelativos emocionales con propuestas bien estudiadas de políticas públicas. Así puede llegar a varios públicos y convencer 
con la razón y los sentimientos de la virtud de sus proyectos y sobre la falsedad y mala fe de sus opositores, sobre todo de los medios.

Ya que los diarios son enemigos del Presidente, de la Patria y de la historia se merecen todo tipo de insultos. El sábado 12 de septiembre, por ejemplo, calificó al Diario El Universo de Guayaquil como "pasquín", "esa porquería", "corruptos", "mediocres", "farsantes" y "payasos". ${ }^{18}$ La beligerancia en contra de los medios llevó a la suspensión temporal del canal Tele Amazonas en diciembre de 2009 y a que las calles de Quito estén llenas de pintadas en contra del periodista Jorge Ortiz, a quien el Presidente descalifica, tratándolo de "enano". Este periodista ha sido atacado e insultado por partidarios del Presidente.

\section{Democracia plebiscitaria y mayoritaria}

La revolución ciudadana encabezada por Rafael Correa se lleva a cabo con "votos y no con balas". La idea de revolución pinta todas las luchas como disputas por valores últimos y sagrados que ponen en juego la existencia misma de la Patria. En estas confrontaciones de proporciones titánicas quienes no están con el líder del proceso son los enemigos de la nación. La intolerancia del discurso maniqueo atenta contra el derecho al disenso y al pluralismo, sin los cuales será muy difícil construir ciudadanías y una democracia participativa. Cada vez se restringe más la independencia de la esfera pública del Estado. Los ataques del Gobierno a la prensa crean un ambiente de autocensura en los medios y cuando los periodistas y editorialistas critican al régimen son amenazados con viejas leyes de desacato y con juicios a la difamación que pueden resultar en multas y encarcelamiento de los críticos.

Esta revolución se asienta en nociones sustantivas de la democracia entendida como la equidad. El Presidente, que nunca fue militante de la izquierda ortodoxa, comparte la distinción de ésta entre democracia formal y democracia real. En una conferencia académica en Oxford diferenció "la democracia formal de derechos políticos, básicamente el derecho al voto" de una "verdadera democracia real, es decir, el derecho a la educación, a la salud, a la vivienda". ${ }^{19}$ Para alcanzar una sociedad más equitativa $\mathrm{o}$, en sus palabras democrática, Correa aumentó el gasto social del 5.3\% del PIB en 2006 al 7.4\% en 2008 (Ramírez y Minteguiaga, 2007: 96). El gasto social pasó de 1.700 millones de dólares en 2006 a 2.700 millones en 2009 (Montúfar, 2010:10). El salario mínimo se incrementó de $\$ 170$ a $\$ 240$ al mes y se eliminó el trabajo subcontratado y precarizado. Se han mantenido los subsidios a la gasolina, gas y electricidad para los más pobres. Es difícil que este nivel de gasto público se pueda sostener si caen los precios del petróleo y es una pregunta abierta si las políticas sociales de esta administración siguen criterios populistas en busca de votos o si son hechas como políticas estatales con criterios universalistas (Weyland, 2009). Además, este incremento del gasto social se asienta en bases coyunturales frágiles debido al aumento de la renta petrolera y no en bases institucionales sólidas que lo haga duradero en el mediano y largo plazo. Pese a la elevación del gasto social la pobreza no se ha reducido en los niveles que podría esperarse. La pobreza bajó antes de que Correa asuma el poder del 49.1\% en 2003 al 37.4\% en 2006. Durante 
la administración de Correa, y tal vez debido a los efectos de la crisis mundial, la pobreza bajó dos puntos y fue del $35.8 \%$ en 2009. El coeficiente de Gini se mantuvo casi estable: fue de 0.54 en 2006 y 0.52 en $2009 .{ }^{20}$

La democracia que se está implementando en Ecuador privilegia sus aspectos mayoritarios y plebiscitarios. Al igual que otros populismos, el gobierno de Correa "es hostil a la idea de derechos y rendición de cuentas, pues dichos instrumentos de limitaciones gubernamentales son herramientas que protegen a las minorías, debilitando en cambio a la voluntad popular" (Peruzzotti, 2008: 111). Ya que el líder populista sostiene encabezar un proyecto de transformación profunda, no respeta los derechos al disenso de las minorías, los procedimientos de la democracia liberal que aseguran la independencia de los diferentes poderes del Estado y los mecanismos de rendición de cuentas horizontales (Madrid, Hunter y Weyland, 2010).

Los procedimientos de la democracia son instrumentalizados en función del proyecto político de Alianza PAIS de acumular hegemonía para transformar la correlación de fuerzas políticas. En 2007 el Gobierno, por ejemplo, destituyó con artimañas legales a 57 parlamentarios y luego la Asamblea Constituyente declaró que el congreso estaba en receso indefinido. Estas acciones fueron autoritarias tanto en la forma en que se llevaron a cabo como en sus consecuencias (Domínguez, 2008: 344). Al igual que sus predecesores populistas el Presidente no siempre se siente atado a la constitución. Muchos de los artículos transitorios sobre minería, agua y seguridad alimenticia han violado el espíritu de la constitución de 2008 . Además se ha concentrado el poder político en la presidencia y se han desmantelando los mecanismos que garantizan la independencia entre los diferentes poderes del Estado que ahora son controlados por el ejecutivo. Como lo anotan Raúl Madrid, Wendy Hunter y Kurt Weyland (2010: 60) "hay un peligro real que la concentración del poder se consolide y asuma cada vez más un carácter autoritario".

Importan más los valores sustantivos de la democracia que las libertades que garantizan que la sociedad civil no esté subordinada al Estado. La participación ciudadana se estatiza y desde el poder se crean y promocionan organizaciones sociales afines al gobierno, a la vez que se fragmentan, debilitan y cooptan a las organizaciones autónomas de la sociedad civil. Es así que al igual que en las experiencias populistas clásicas y neopopulistas se subvierten las actividades organizacionales autónomas de los movimientos sociales y su capacidad para la acción colectiva autónoma del Estado (Oxhorn, 1998: 225).

\section{Conclusiones}

El gobierno izquierdista de Rafael Correa, al igual que otros gobiernos progresistas, ha abandonado la ortodoxia neoliberal. Se ha devuelto un rol central a la planificación estatal para que regule y coordine la política económica. Al igual que los gobiernos de Chávez y Morales su gobierno se ha beneficiado del incremento de la renta petrolera. Esto ha permitido subir el gasto social y además el Gobierno ha dejado de lado la cautela de los neoliberales y ha invertido en programas de desarrollo los fondos de los excedentes petroleros, que antes se los guardaba 
como precaución para momentos de crisis. Parecería que sus políticas sociales se asientan en bases institucionales frágiles y no en bases que puedan mantenerse al mediano y largo plazo, si es que bajan los precios del petróleo. Además, habría que explorar si sus políticas sociales son universalistas o siguen el patrón neoliberal de focalizar pero con el agravante de ser usadas, como lo hace Chávez, con fines electorales.

Pese a que el plan de gobierno con el que llegó al poder y la constitución de 2008 señalan a la democracia participativa como una alternativa a la representativa, todavía no se crean instituciones para ejercerla. El momento de mayor participación de su gobierno, que fue el proceso constituyente, estuvo limitado por la figura del presidente carismático que vetó algunos temas y que impuso su criterio en otros. Además y pese a la promesa de que la planificación estatal se basaría en la participación de la sociedad civil, por lo pronto la participación se reduce a escuchar las propuestas técnicas del gobierno que son socializadas ante diferentes audiencias en presentaciones en power point. La democracia participativa se reduce a la aclamación plebiscitaria al líder en elecciones y durante sus enlaces sabatinos.

El gobierno de Rafael Correa prometió una revolución ciudadana que mejore los déficit de la democracia representativa. Al igual que en otros gobiernos de izquierda se hizo una asamblea refundacional. La nueva constitución amplió los derechos. Pero ya que el Presidente se ve como la encarnación de la revolución ciudadana y de la futura redención de la nación no respeta los derechos al disenso ni el pluralismo. Su visión de democracia mayoritaria le ha llevado a concentrar el poder en el ejecutivo y a subordinar a los diferentes poderes del Estado a éste. Además, se confunde rendición de cuentas con los enlaces en que el Presidente cuenta lo que le pasó a él, al Estado y a la patria. Los mecanismos de rendición de cuentas horizontal no funcionan y se asume que el acto electoral otorga al mandatario el poder para gobernar de acuerdo a lo que considere que es lo mejor para la patria que él dice encarnar.

La estrategia mediática que busca ligar al presidente con el pueblo, que ha sido muy eficaz para ganar elecciones, es un sustituto pobre para las promesas de la revolución ciudadana de devolver el poder a éstos y de crear una mejor democracia. Por último, el Gobierno ha usado la estrategia populista de cooptar y desradicalizar a los movimientos sociales (Oxhorn, 1998). Si continúan estas tendencias un legado del gobierno izquierdista de Correa será dificultar aún más las posibilidades que tienen los sectores populares para emprender acciones colectivas autónomas del Estado.

\section{Referencias}

1. Plan de Gobierno de Alianza País 2007-2011, p. 19.

2. Ibídem, p. 20.

3. "Será indispensable la movilización social", Expreso, Guayaquil, 04/12/06. Disponible en: http:// www.expreso.ec/htlm/politica1.asp.

4. Entrevista a Rocío Rosero, enero de 2008 e intervención en la FLACSO el 25 de enero del mismo año. Entrevista a Nina Pacari, enero de 2008. 
5. El Comercio, Quito, 28/03/2008, p.6. El Comercio, Quito, 02/02/2008, p. 3.

6. Las mesas fueron: 1) derechos fundamentales y garantías constitucionales; 2) organización, participación social y ciudadanía y sistemas de representación; 3) estructura e instituciones del Estado; 4) ordenamiento territorial y asignación de competencias; 5) recursos naturales y biodiversidad; 6) trabajo, producción e inclusión social; 7) régimen de desarrollo; 8) justicia y lucha contra la corrupción; 9) soberanía, relaciones internacionales e integración latinoamericana; 10) legislación y fiscalización.

7. La Constituyente Avanza, suplemento institucional, El Comercio, Quito, 13/05/2008.

8. Discurso de Posesión del Presidente de la República, economista Rafael Correa, Quito, 10/08/2009.

9. Carta de Rocío Rosero al presidente Rafael Correa, 03/01/2008.

10. Rafael Correa, "Informe a la Nación en el Inicio del Tercer Año de Revolución Ciudadana”, Quito, 19/01/2009, Plaza de la Independencia.

11. Enlace Ciudadano $N^{\circ} 139,26 / 09 / 2009$.

12. Rafael Correa, "Intervención Presidencial en el Acto de Entrega de Armas en el Comando Provincial de Manabí”, Portoviejo, 12/03/2009.

13. El publicista Vinicio Alvarado, amigo de la niñez de Correa, que realizó la publicidad en su campaña electoral es el Secretario General de la Administración y está a cargo del equipo que diseña la estrategia mediática del Gobierno.

14. El Comercio, 03/01/2010.

15. En 2008, 176 de un total de 187 cadenas se centraron en el Presidente (Montúfar, 2010: 8).

16. El Gobierno controla el medio impreso estatal El Telégrafo y el medio digital El Ciudadano. También las empresas de televisión directa TC Televisión, Gama Visión y el canal de televisión por cable Cablevisón que fueron expropiados a los banqueros Isaías. Además se conformó el canal público Tevecuador y el Estado controla cuatro estaciones de radio. Los enlaces ciudadanos son retransmitidos por alrededor de 400 estaciones de radio locales y nacionales y por dos canales de televisión.

17. Enlace Ciudadano No $131,01 / 08 / 2009$.

18. Enlace Ciudadano 137, 12/09/2009.

19. "Experiencia de un Cristiano de Izquierda en un Mundo Secular", Oxford Union Society, 26/10/2009.

20. Datos no publicados de FLACSO-Ecuador.

\section{Bibliografía}

A. ACOSTA (2009) "La maldición de la abundancia: un riesgo para la democracia", en Revista La Tendencia, $\mathrm{N}^{\circ}$ 9, (March-April).

A. ARATO (2005), "Constitutional Learning”, en Theoria: a Journal of Political and Social Theory, abril.

J. CASTAÑEDA (2006), "Latin America's LeftTurn”, en Foreign Affairs, № 85.

C. CONAGHAN (2008), "Ecuador: Correa's Plebiscitary Presidency”, en Journal of Democracy, Vol. $19, \mathrm{~N}^{\mathrm{o}} 2$.

C. CONAGHAN y C. DE LA TORRE (2008), "The Permanent Campaign of Rafael Correa: Making Ecuador's Plebiscitary Presidency", en International Journal of Press/Politics, № 13.

J. DOMÍNGUEZ (2008), "Three decades since the Start of the Democratic Transition", en J. DOMÍNGUEZ y M. SHIFTER (eds.), Constructing Democratic Governance in Latin America, Baltimore, The Johns Hopkins University Press.

J. FRENCH (2009), "Understanding the Politics of Latin America's Plural Lefts (Chavez/Lula): social democracy, populism and convergence on the path to a post-neoliberal world", en Third World Quarterly, $\mathrm{N}^{\circ} 30$.

C. GEERTZ (1985), "Centers, Kings, and Charisma: Reflections on the Symbols of Power", en S. WILENTZ (ed.), Rites of Power: Symbolism, Ritual, and Politics since the Middle Ages, Philadelphia, University of Pennsylvania Press.

E. HURTADO (2005), "Lo que pasó en CIESPAL. Apuntes etnográficos sobre el poder, los medios y los sin-sentidos de la violencia”, en Í́conos, № 23. 
T. LARREA (2007), ¿En qué pensamos los ecuatorianos al hablar de democracia?, Participación Ciudadana.

A. M. LARREA (2008), “La Plurinacionalidad. Iguales y diversos en busca del Sumak Kawsay”, en K. LUCAS (ed.), Entre el quiebre y la realidad. Constitución del 2008, Quito, Abya Yala.

R. MADRID, W. HUNTER y K. WEYLAND (2010), "The Policies and Performance of the Contestarory and Moderate Left", en R. MADRID, W. HUNTER y K. WEYLAND (eds.), Leftist Governments in Latin America: Successes and Shortcomings, Cambridge, Cambridge University Press (en prensa).

C. MARTINEZ NOVO (2009), “The Indigenous Movement and the Citizen's Revolution in Ecuador: Advances, Ambiguities, and Turn Backs. Unpublished Paper delivered for the Conference "Outlook for Indigenous Politics in the Andean Region, Center for Strategic International Studies, Washington DC.

C. MONTÚFAR (2010), "Rafael Correa y su Refundación Constituyente”, Woodwrod Wilson Center, manuscrito no publicado.

N. ORNSTEIN and T. E. MANN (2000), "Conclusion: The Permanent Campaign and the Future of American Democracy", en N. ORNSTEIN and T. E. MANN (eds.), The Permanent Campaign and its Future, Washington DC., American Enterprise Institute Press.

P. OSPINA (2009), "Corporativismo, Estado y Revolución Ciudadana. El Ecuador de Rafael Correa", manuscrito no publicado.

P. OXHORN (1998), “The Social Foundation of Latin America's Recurrent Populism: Problems of Popular Sector Class formation and Colective Action", en Journal of Historical Sociology N 11 (2).

S. PACHANO (2010), "Democracia representativa y mecanismos de democracia directa y participativa", manuscrito no publicado.

F. PANIZZA (2005), "Unarmed Utopia Revisited: The Resurgence of Left-of-Centre Politics in Latin America", en Political Studies, № 53 (4), Oxford.

Y. PERI (2004), Telepopulism. Media and Politics in Israel, Stanford, Stanford University Press.

E. PERUZZOTTI (2008), "Populismo y representación democrática", en C. DE LA TORRE y E. PERUZZOTTI (eds.), El retorno del pueblo. El populismo y nuevas democracias en América Latina, Quito, FLACSO.

F. RAMÍREZ GALLEGOS y A. MINTEGUIAGA (2007), "El nuevo tiempo del Estado. La política posneoliberal del correismo", en OSAL, Buenos Aires, CLACSO, año VII, № 22, septiembre.

R. ROSERO, M. P. VELA y A. REYES (2000), De las demandas a los derechos. Las mujeres en la Constitución de 1998, Quito, CONAMU.

R. SEGURA y A. M. BEJARANO (2004), “¡Ni una asamblea más sin nosotros! Exclusion, Inclusion, and the Politics of Constitution-Making in the Andes", en Constellation, Vol. 11, No 2.

K. WEYLAND (2009), "The Rise of Latin America's Two Lefts. Insights from Rentier State Theory", en Comparative Politics, $\mathrm{N}^{\mathrm{o}} 41$ (2).

Recibido: 02/05/2010. Aceptado: 10/08/2010.

Carlos de la Torre, "El gobierno de Rafael Correa: posneoliberalismo, confrontación con los movimientos sociales y democracia plebiscitaria". Revista Temas y Debates. ISSN 1666-0714, año 14, número 20,

octubre 2010, pp 157-172. 